\title{
Pandemia y 24 de marzo. Visualidades emergentes del activismo online yoffline (2020-2021)
}

\author{
Pandemic and March 24 in Argentina. Emerging visualities of online and offline \\ activism (2020-2021)
}

\author{
Melina Jean Jean \\ melinajeanjean@gmail.com \\ Instituto de Investigaciones en Humanidades y \\ Ciencias Sociales (IdIHCS). Universidad Nacional \\ de La Plata / CONICET, Argentina
}

\author{
María Emilia Nieto \\ mariaemilianieto@gmail.com \\ Instituto de Investigaciones en Humanidades y \\ Ciencias Sociales (IdIHCS). Universidad Nacional \\ de La Plata / CONICET, Argentina
}

\author{
Verónica Capasso \\ capasso.veronica@gmail.com \\ Instituto de Investigaciones en Humanidades y \\ Ciencias Sociales (IdIHCS). Universidad Nacional \\ de La Plata / CONICET, Argentina
}

Cita sugerida: Jean Jean, M., Nieto, M. E. y Capasso, V.

(2021). Pandemia y 24 de marzo. Visualidades emergentes del activismo online y offline (2020-2021). Aletheia, 11(22), e094. https://doi.org/10.24215/18533701e094

\begin{abstract}
Resumen: El 24 de marzo en Argentina es una fecha en la cual se realizan en todo el país marchas y actos encabezados por las organizaciones de derechos humanos en conmemoración de las víctimas de la última dictadura cívico-militar iniciada en 1976. Sin embargo, durante los años 2020 y 2021 esta fecha estuvo signada por diferentes condicionamientos dado el Covid-19. En contexto de ASPO y DISPO, ¿qué memorias se activaron y pusieron a circular esos días? ¿Qué soportes y herramientas fueron fundamentales? ¿Cómo fueron esos paisajes visuales de la memoria? ¿Cómo se conjugaron el activismo offline y el activismo online? Estas son algunas de las preguntas que se irán desentrañando a lo largo del texto. A partir del análisis, se observa una (re)configuración en los modos de hacer memoria colectiva que implicó nuevos desafíos a la hora de pensar su defensa/ disputa y transmisión. Asimismo, hubo una renovación de las estrategias visuales desde las materialidades y formas y desde los modos de circulación, a la vez que se sumaron voces y luchas del presente que reavivaron el sentido de los trabajos de memoria para visibilizar problemáticas actuales y ampliar derechos que consoliden la democracia.
\end{abstract}

Palabras clave: Visualidades, Pandemia, Memoria, 24 de marzo, Activismo offline, Activismo online.

\begin{abstract}
March 24 in Argentina is a date on which marches and events led by human rights organizations are held throughout the country in commemoration of the victims of the last civicmilitary dictatorship that began in 1976. However, during the years 2020 and 2021 this date was marked by various constraints given the Covid-19. In the context of ASPO and DISPO, what memories were activated and circulated those days? What supports and tools were essential? How were those visual landscapes of memory? How did offline activism and online activism come together? These are some of the questions that will be unraveled throughout the text. From the analysis, a (re) configuration is observed in the ways of making collective memory that implied new challenges in its defense/dispute and transmission. There was also a renewal of visual strategies from materialities and forms and modes from circulation, at the same time that voices and struggles of the present were added that revived the meaning of memory works to make current problems visible and expand rights that consolidate democracy.
\end{abstract}

Keywords: Visualities, Pandemic, Memory, March 24, Offline activism, Online activism. 


\section{INTRODUCCIÓN}

El 24 de marzo en Argentina, Día Nacional de la Memoria por la Verdad y la Justicia, es una fecha en la cual se realizan en todo el país marchas y actos encabezados por las organizaciones de derechos humanos en conmemoración de las víctimas de la última dictadura cívico-militar iniciada formalmente aquel día en 1976. El año pasado, 2020, el contexto fue diferente dada la situación mundial de pandemia (por el Covid-19) y la cuarentena obligatoria decretada por el gobierno nacional, efectiva a partir del 20 de marzo. Desde ese día, todo el país estuvo bajo lo que se conoció como ASPO -aislamiento social, preventivo y obligatorio- en el cual, salvo pocas excepciones, todas las actividades sociales, laborales y comerciales quedaron suspendidas en su forma presencial. El 13 de marzo, es decir, unos días antes, previendo el panorama, los organismos tomaron la decisión definitiva de cancelar la histórica marcha hacia Plaza de Mayo en la ciudad de Buenos Aires y todas las actividades tradicionales que la acompañaban. En ese marco los pañuelazos en las casas particulares se constituyeron en el eje de las intervenciones y las redes sociales se poblaron de fotografías que buscaron construir y registrar esta campaña.

El contexto en el cual se desarrolló el 24 de marzo de 2021 fue diferente al año anterior. Si bien la pandemia generada por el Covid-19 aún atraviesa y configura nuestras vidas, esta fecha transcurrió en DISPO, es decir en distanciamiento social, preventivo y obligatorio. Es importante mencionar que, sin descuidar los protocolos, desde finales del 2020, el DISPO permitió (permite) un nuevo marco normativo para la realización de actividades sociales, culturales, comunitarias y recreativas al aire libre. Esto favoreció un uso extendido del espacio público como punto de reunión de familias, amigues y grupalidades diversas en un contexto de cuidado del otre. Es por ello que muchas actividades comenzaron a realizarse en plazas, parques, ramblas y demás espacios verdes de las ciudades.

¿Qué memorias se activaron y pusieron a circular esos días? ¿Qué soportes y herramientas fueron fundamentales? ¿Qué genealogías hay detrás de estas iniciativas? Estas son, entre otras, algunas de las preguntas que surgen en un momento en que se vuelve fundamental reinventar las estrategias de intervención y construcción de memorias en el marco de una "nueva normalidad" donde el distanciamiento sanitario es primordial. En este sentido, planteamos que en ambas fechas, aunque de diferentes formas, adquirió centralidad la visualidad, como campo amplio, que supone formas culturales vinculadas a la mirada, a circunstancias de producción y variedad de funciones culturales, sociales y políticas de las imágenes en situaciones sociales específicas, como la que aquí se aborda (Mitchell, 2009). Asimismo, hoy en día, los repertorios visuales no pueden pensarse por fuera del mundo virtual. El desarrollo de las tecnologías y el uso masivo de internet no solo han impactado y transformado nuestra vida cotidiana sino también los modos de comunicar a través de las imágenes. Lo mismo se observa en las formas en las que accedemos a nuestro pasado, a los modos en que registramos, elaboramos representaciones y construimos sentidos sobre él. En este sentido, los procesos de digitalización e interconexión asociados a la web 2.0 están redefiniendo y transformando nuestra relación con el pasado y las dinámicas de construcción de memoria (Erll y Nünning, 2011; Trujillo Amaya y García Hernández, 2017). A pesar de las diferentes opiniones, un presupuesto común es que la mediación digital o el denominado "giro digital" (Runnel, Pruulmann-Vengerfeldt, Viires, Laak, 2013; Westera, 2013; Bresciano y Gil, 2015; Ejido y Eiroa, 2017; Mandolessi, 2019) introdujo cambios en las dinámicas sociales del recuerdo y el olvido y en la producción y circulación social de la memoria.

El activismo del movimiento de derechos humanos en Argentina ha conquistado el espacio público luego de muchos años de resistencia, de lucha, y del trabajo conjunto en políticas públicas de memoria gestionadas 
con el Estado. Sus acciones han intervenido y creado lugares de memoria a lo largo y ancho de todo el país. Sin embargo, la pandemia obligó al movimiento a experimentar de manera colectiva y coordinada ${ }^{1}$ los espacios virtuales, moviéndose entre los pliegues del activismo online y offline, es decir, como ya veremos, entre las redes sociales, los hogares y el espacio público. Sin pretender dar respuesta a todos los interrogantes que emergen, este caso nos convoca a reflexionar sobre las transformaciones en el repertorio visual del activismo durante estas jornadas. Y en el impacto y los alcances de los trabajos de memoria en el presente, atravesados en gran medida por el advenimiento de las nuevas tecnologías, medios y dispositivos conectados a Internet y el mundo virtual.

¿Son acaso las conmemoraciones del 24 de marzo durante la pandemia un hito dentro del repertorio activista del movimiento de derechos humanos en Argentina? ¿Será que hay prácticas y creaciones nuevas que llegaron para quedarse?

\section{M20: Pañuelazos en las casas Para No OLVIDAR}

El 24 de marzo de 2020 estuvo signado por el imperativo del aislamiento, a muy pocos días de la implementación de las primeras medidas sanitarias. Frente a la imposibilidad de movilización en las calles, el activismo se trasladó a los hogares y las redes sociales. Por un lado, el 17 de marzo, las Abuelas de Plaza de Mayo comenzaron a difundir en su sitio web y todas sus redes (Instagram, Twitter, Facebook, Youtube) una convocatoria que invitaba a subir una foto, con la consigna "Contanos por qué es importante recordar. No olvides usar \#MesDeLaMemoria \#ConstruimosMemoria. Etiquetanos” (Imagen 1). Las fotos podían ser registros de las marchas anteriores, de eventos y producciones de todo tipo. Por otro lado, el 20 de marzo, los organismos en su conjunto lanzaron, a través de sus plataformas, una convocatoria particular que denominaron "Pañuelazo Blanco" ${ }^{2}$ con la consigna:

Este 24 de marzo, subí a redes sociales fotos con pañuelos blancos, colgalos en tu balcón, puerta o ventana. No podemos marchar pero la Memoria sigue intacta. \#PañuelosConMemoria. ${ }^{3}$ (Imagen 2) 
Imagen 1: Flyer de la convocatoria "Pañuelazo blanco" divulgado en historias del Instagram oficial de Abuelas de Plaza de Mayo, 24 de marzo de 2020.

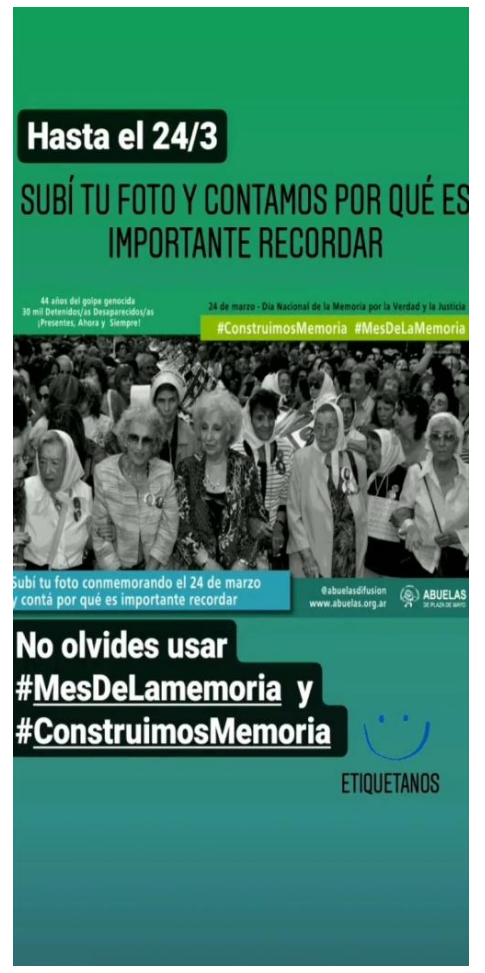

Imagen 2: Flyer de la convocatoria "Pañuelazo blanco" divulgada por los organismos de derechos humanos en Argentina, 24 de marzo de 2020.

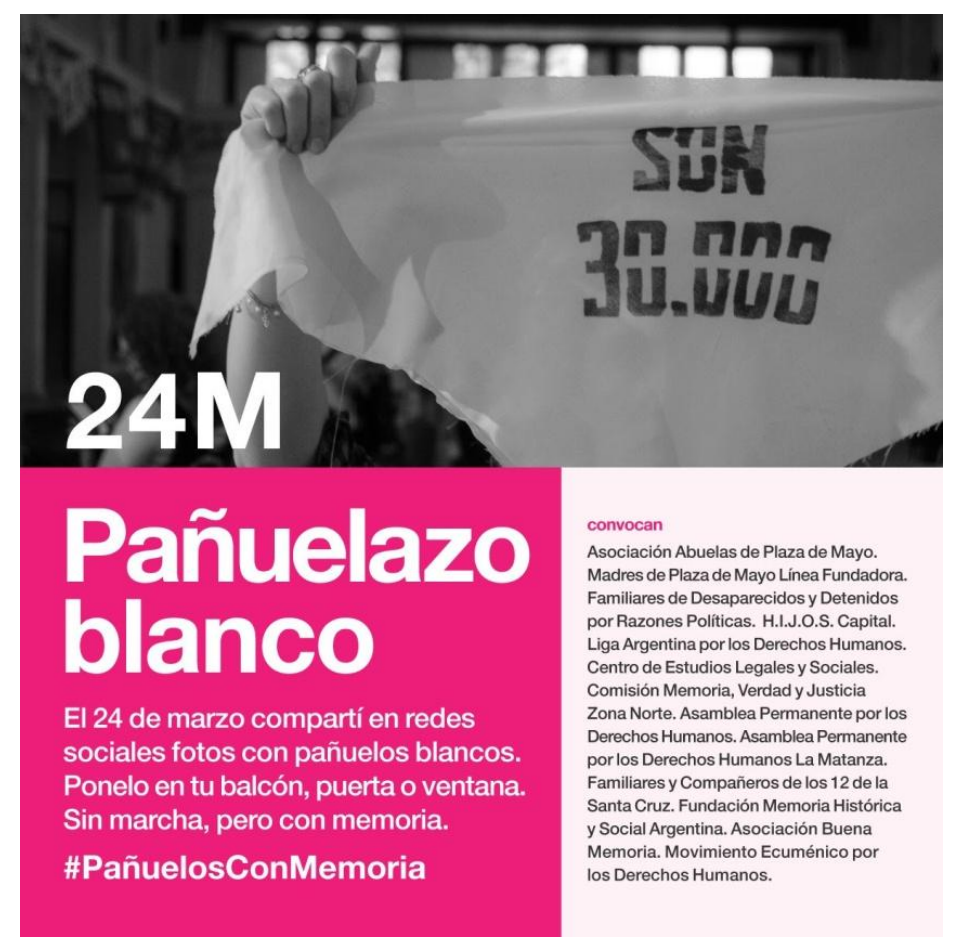

Esta última acción memorial, públicamente, adquirió el reconocimiento y la cualidad de funcionar como el correlato virtual de la histórica marcha, cancelada por primera vez en la historia. Esta vez, al igual que en su antecedente, el "pañuelazo" del "2x1" en Plaza de Mayo el 10 de mayo de $2017^{4}$, el pañuelo fue autorizado y promovido por sus portadoras para ser utilizado masivamente por quienes participaran y adhieran a la causa. 
Esta convocatoria provocó numerosas intervenciones que se movieron en los pliegues del activismo offline y online: acciones en las casas cuyos registros digitalizados fueron compartidos posteriormente en las redes sociales y a través de transmisiones en directo. Si bien los entornos virtuales necesariamente funcionaron como medios para la convocatoria, difusión y circulación, su uso posibilitó la producción de ciertas visualidades digitales que no solo funcionaron como representaciones de determinadas memorias -la lucha de las Madres y Abuelas, los “30mil”, el “nunca más", "fue genocidio”, entre otras consignas y demandassino también como un entramado de tecnologías y prácticas -materiales, discursivas, afectivas- que mediaron en la interacción y contribuyeron a la configuración del "24M20" como un fenómeno virtual sin precedentes, en el cual el pañuelo blanco fue el elemento simbólico elegido para visualizar esa fecha.

Aquí se torna fundamental pensar en aquello que Gamarnick (2020) señala como las dimensiones visuales de la lucha o la protesta social y el lugar fundamental que ocupan les productores de imágenes en las movilizaciones. En este caso, podríamos pensar que los pañuelos se constituyeron en el actor por excelencia. Dada la imposibilidad de movilizarse en la calle, la producción de la imagen, su registro y puesta en circulación se volvieron/vuelven en sí mismas una forma de la movilización. La consigna de utilizar el pañuelo blanco en el hogar fue sencilla y bien aceptada, les usuaries tuvieron la libertad de confeccionarlos con materiales que tuvieran al alcance. Luego, se necesitó de celulares, computadoras y tablets para poner a circular fotografías, videos y ediciones; hashtags con consignas y textos alusivos; para subir historias, crear tuits y hacer posteos, etc. Las redes sociales se poblaron de pañuelos blancos que, sin dudas, se convirtieron en la representación visual del 24M20.

Vale decir que, en las últimas décadas, la utilización de recursos estéticos y visuales como modo de poner en escena diferentes demandas, ha ido ocupando cada vez más espacio en diversidad de manifestaciones sociales. La nueva coyuntura que abre la pandemia instala esto con mayor centralidad.

\section{M21: PLANTAR MEMORIA Y MOVILIZAR EN CARAVANA}

Como ya dijimos, los actos vinculados al 24 de marzo del 2021, $45^{\circ}$ aniversario del golpe cívico-militar, adquirieron otro formato, diferente al tradicional pero también distinto al modo de recordar del 2020. A un año de la pandemia, las propuestas para este nuevo aniversario del golpe del ' 76 pudieron ser pensadas con más tiempo, a la vez que otro tipo de acciones han sido posibles al haber mayor circulación en el espacio público.

En primer lugar, las Abuelas de Plaza de Mayo, mediante un comunicado, confirmaron que harían acciones conmemorativas colectivas pero que "Este año, al igual que el pasado, no vamos a marchar a la histórica Plaza de Mayo ni convocaremos a concentraciones multitudinarias en la ciudad de Buenos Aires"5. En este marco, los organismos de derechos humanos propusieron "Plantamos Memoria"6, una campaña nacional de plantación y difusión por redes sociales. La propuesta se basó en sembrar árboles, plantas, arbustos en macetas o en la tierra, asociando dicho acto, metafóricamente, con el hecho de sembrar memoria. Se invitó a quienes participaran, a que fotografíen la propuesta y difundan en Facebook, Twitter, Instagram con los hashtags \#PlantamosMemoria, \#45añosDelGolpeGenocida y \#Son30mil. Esta iniciativa fue llevada adelante por muchas escuelas públicas durante la semana del 24 de marzo, en el contexto del retorno a la presencialidad educativa. Recordemos que, en nuestro país, las luchas por Memoria, Verdad y Justicia dieron lugar a una Pedagogía de la Memoria que se instaló con más fuerza a partir del año 2006 con la sanción de la Ley de Educación Nacional. En ésta se introdujo el 24 de marzo en el calendario escolar, con el estatus de feriado nacional inamovible, además del tratamiento obligatorio de contenidos relacionados con la historia reciente y la memoria, como parte de los diseños curriculares comunes a todas las provincias (como queda establecido en su artículo 92). Junto con estas iniciativas se pusieron en marcha programas educativos, políticas de formación docente y producción de materiales pedagógicos que tomaron como eje la transmisión de memorias sobre ese pasado reciente (Legarralde y Brugaletta, 2017). En este marco la iniciativa de "plantar memoria" tuvo mucha recepción en los espacios educativos, constituyéndose en 
una de las actividades fundamentales de esa semana, realizadas en escuelas primarias, secundarias y también en algunas universidades. Asimismo, también el Gobierno de la Provincia de Buenos Aires se sumó a la convocatoria con una propuesta particular: plantar un árbol de la flora nativa bonaerense para lo cual divulgaron un listado en el que también ofrecieron recomendaciones para el plantado y cuidado ${ }^{7}$. Por otra parte, debemos mencionar que la acción de plantar un árbol en homenaje y conmemoración a víctimas es, o al menos ha sido, recurrente a partir del "boom" de memoria (Huyssen, 2002) a inicios de este siglo. Sin embargo, nunca antes había sido la convocatoria principal a nivel nacional (e internacional) de una jornada colectiva tan importante en el país como el 24 de marzo.

Además de la campaña "Plantamos Memoria" en diversas instituciones -en escuelas y universidades, pero también dependencias estatales, sindicatos, etc.-, se realizaron otro tipo de acciones. Por ejemplo, se colgaron pañuelos blancos en las casas, se intervino Plaza de Mayo con los rostros de los 30.000, el Gobierno hizo un mapping en la Casa Rosada con imágenes alusivas ${ }^{8}$, entre otros. Asimismo, y dado el contexto de DISPO, hubo movilizaciones a pie o en auto en las calles de muchas ciudades del país. En la ciudad de La Plata, los organismos que tradicionalmente convocan a realizar la marcha y la exposición de las fotografías de les desaparecides en la Plaza San Martín, organizaron en esta ocasión una caravana de autos con el lema "La Memoria está en la calle”. De esta forma, Madres de Plaza de Mayo La Plata, H.I.J.@.S La Plata, Familiares de detenidxs desaparecidxs y presxs por razones políticas y gremiales, NIETES, la Asamblea Permanente por los Derechos Humanos, entre otras agrupaciones, realizaron la "Caravana por la Memoria, la Verdad y la Justicia” que comenzó en el Ex BIM 3 y culminó frente a Tribunales en 8 y 50, con la lectura del habitual documento. Las fotografías de les desaparecides fueron colgadas en la plaza y en otros puntos del trayecto como por ejemplo en el Registro Provincial de las Personas en 1 y 60.

En Berisso la Comisión Permanente por la Memoria de Berisso en conjunto con la Dirección de Derechos Humanos del municipio, realizaron la tradicional Vigilia por Memoria, Verdad y Justicia la noche del 23, frente al Monumento a los desaparecidos ubicado en el Parque Cívico de la ciudad. ${ }^{9}$ Desde las 21 hs. se proyectaron videos e intervenciones culturales realizadas por artistas locales, se colocó una placa y se plantaron 4 árboles nativos. Como cada año se colocaron las sillas identificándolas con el nombre de les compañeres detenides-desaparecides, y sus familiares e hijes colocaron prendas de sus padres y madres sobre ellas. ${ }^{10}$ La jornada cerró a la medianoche con la lectura de los nombres de les desaparecides de Berisso y fue transmitida en vivo a través del Facebook oficial de la Comisión y la radio de la Municipalidad. ${ }^{11}$ En Ensenada el día 23, Aguas Bonaerense S.A (ABSA) inauguró el "Bosque de la Memoria” en la Planta Potabilizadora Donato Gerardi de Punta Lara y se plantaron 10 árboles nativos. Por otra parte, el miércoles 24, ATE convocó a un acto en el Monumento de la Memoria del Astillero Naval Río Santiago para recordar a les trabajadores detenides-desaparecides y se plantaron árboles por la memoria. ${ }^{12}$ También ese día el municipio junto con familiares plantaron árboles en el predio donde se está construyendo el nuevo Parque Madres de Plaza de Mayo. ${ }^{13} \mathrm{La}$ actividad se realizó en el marco de toda una serie de intervenciones, realizadas los días siguientes: el 26 se inauguró un mural en el barrio YPF, en homenaje a la familia Kennel-Medina ${ }^{14}$, el 29 se convocó a "plantar memoria" en la Plaza "Julio López" de la localidad de Punta Lara ${ }^{15}$ y el 30 se realizó la señalización de la esquina de las calles Eva Perón y Barragan, en memoria de los compañeros desaparecidos Juan Carlos Blasetti y Ruben Omar Padin. ${ }^{16}$ En Villa Elisa, el colectivo de Vecinos de Villa Elisa por Memoria, Verdad y Justicia, también llevaron adelante diversas iniciativas, principalmente se reunieron el 24 por la mañana a sembrar en el Parque Pereyra Iraola, en la parada "El Palenque" (Camino general Belgrano Km. 38), sitio donde tuvieron la histórica reunión en 1977 las Madres de Plaza de Mayo ${ }^{17}$. Por la noche realizaron como cada año la iluminación del Paseo de la Memoria, donde familiares y compañeres acercaron sus velas al mural, para homenajear a les 25 desaparecides de la localidad. ${ }^{18}$

Es preciso destacar que el 2021 estuvo signado con más fuerza por los debates en torno a la necesidad de retomar las manifestaciones en las calles, en un contexto de DISPO, que como señalamos, habilitó cierta 
circulación. Tras un año de aprendizajes en torno a las medidas de cuidado y protocolos necesarios para llevarlas adelante, algunas organizaciones comenzaron ya hacia fines de 2020 a impulsar manifestaciones con las medidas necesarias para garantizar los cuidados. En este marco el Encuentro Memoria Verdad y Justicia junto con el Frente de Izquierda de Trabajadores Unidad (FIT-U) y otras organizaciones políticas y sociales, sostuvieron la convocatoria a movilizar desde la Plaza de los dos Congresos hasta Plaza de Mayo el día 24. De aquella actividad participaron de manera virtual Nora Cortiñas, Mirta Baravalle, Elia Espen y Elsa Pavón, de Madres de Plaza de Mayo Línea Fundadora. Por otra parte, en La Plata, además de la caravana antes mencionada, la Multisectorial La Plata, Berisso y Ensenada, que nuclea a organismos de derechos humanos de la región, (entre ellos HIJOS La Plata e HIJAS La Plata-Ensenada) convocaron a marchar como cada año, el día 23. La movilización se realizó a las 17 hs., luego de la intervención de un siluetazo en la Plaza San Martín. ${ }^{19}$

\section{¿Nuevos? PAISAJES VISUALES DE LA MEMORIA}

El uso y construcción de imágenes para la configuración de formas de rememoración, nos permite ver cómo la imagen sirve tanto como soporte del recuerdo como también vehículo de memoria. Así, los diferentes lenguajes visuales pueden remitir al pasado e interpelar desde el presente.

Si bien ha habido una profusión de imágenes en circulación en relación al 24M20 y al 24M21, hemos seleccionado un recorte que creemos representativo de las características centrales vinculadas, concretamente, a los diversos soportes, materiales, frases y consignas usadas, agentes o emprendedores, espacios de circulación e inscripción, etc., que puso en evidencia el contexto particular de cada fecha. En relación al 24M20, el recorte proviene de imágenes que circularon exclusivamente en redes sociales: Instagram y Twitter. Durante la observación y el relevamiento online fuimos armando nuestro corpus de fuentes digitales conformado por capturas de pantalla de historias (Instagram) y tuits (Twitter) de diferentes organismos y usuaries. La selección de las propuestas del $24 \mathrm{M} 21$ incluye no solo aquellas que circularon de manera virtual sino que se incorpora, nuevamente, el uso e intervención colectiva y presencial del espacio público.

El 24M20 estuvo signado, como ya mencionamos, por las restricciones impuestas por el ASPO. Es decir, básicamente, por la imposibilidad de reunión y circulación masiva en el espacio público. Por ende, las propuestas de ese día mostraron por un lado, historias de tipo individual, dando cuenta del contexto de encierro bajo el lema \#quedateencasa. Por otro lado, los registros del pañuelazo se socializaron a través de las redes sociales, lo cual permitió conformar una gran comunidad online pidiendo memoria, verdad y justicia, reivindicando todo lo que los pañuelos simbolizan. En ellos podemos observar, sobre todo, la manufactura casera y los espacios que ocuparon colocados en balcones, rejas y puertas de casas particulares. Asimismo, destacamos algunos rasgos específicos de estas propuestas: los pañuelos blancos con inscripciones en formato de hashtags (por ejemplo, “\#Son 30000”, “\#MemoriaVerdadJusticia”, “\#Nunca más”, etc.); el uso tanto de papel como de tela para confeccionarlos; la participación también de niñes dibujando los pañuelos, es decir el involucramiento de la familia en el acto de recordar; el vínculo entre el pañuelo blanco de las madres y abuelas con el pañuelo verde utilizado por la Campaña Nacional por el Derecho al Aborto Legal, Seguro y Gratuito y por quienes adhieren a la causa; la cifra " 30.400 " reclamada por el activismo LGBT $+{ }^{20}$; la incorporación de la wiphala, símbolo de los pueblos originarios de Abya Yala. 
Imagen 3: Desde el sitio “Abuelas Difusión” de las Abuelas de Plaza de Mayo, compartieron a través de historias, las historias de les usuaries que respondieron a la convocatoria "Pañuelazo blanco". Instagram, captura de pantalla, 24 de marzo de 2020.

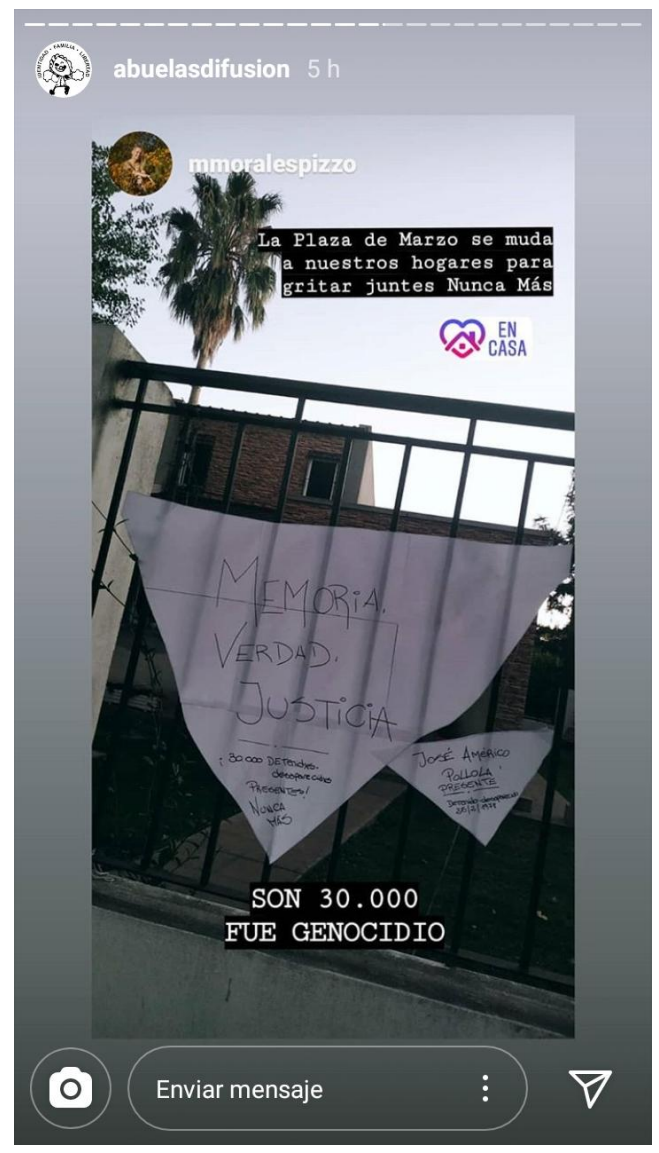

Imagen 4: Tuit personal. Confección alegórica del pañuelo blanco, Campaña \#PañuelazoConMemoria, captura de pantalla, Twitter, 24 de marzo de 2020.

Cristina Britez $=$ @cbritezmisiones · 24 mar.

Este \#24marzo honramos como todos los años nuestro compromiso y nuestra búsqueda de \#MemoriaVerdadYJusticia. No hay pandemia ni aislamiento que menoscabe el recuerdo de los 30.000 desaparecidos ni la permanente lucha contra la impunidad. \#PañuelazoConMemoria

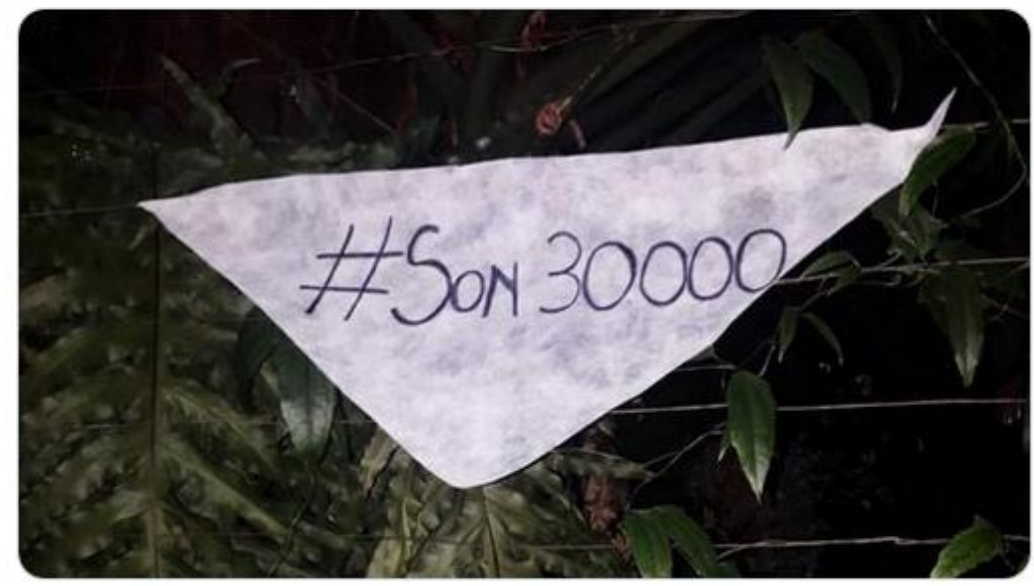

Abuelas Plaza Mayo y H.I.J.O.S. Capital
Q 7
〔】 107
O 199
个 
Imagen 5: Tuit personal. Pañuelos intervenidos con consignas y dibujos de niñes para la Campaña \#PañuelazoConMemoria. Captura de pantalla, Twitter, 24 de marzo de 2020

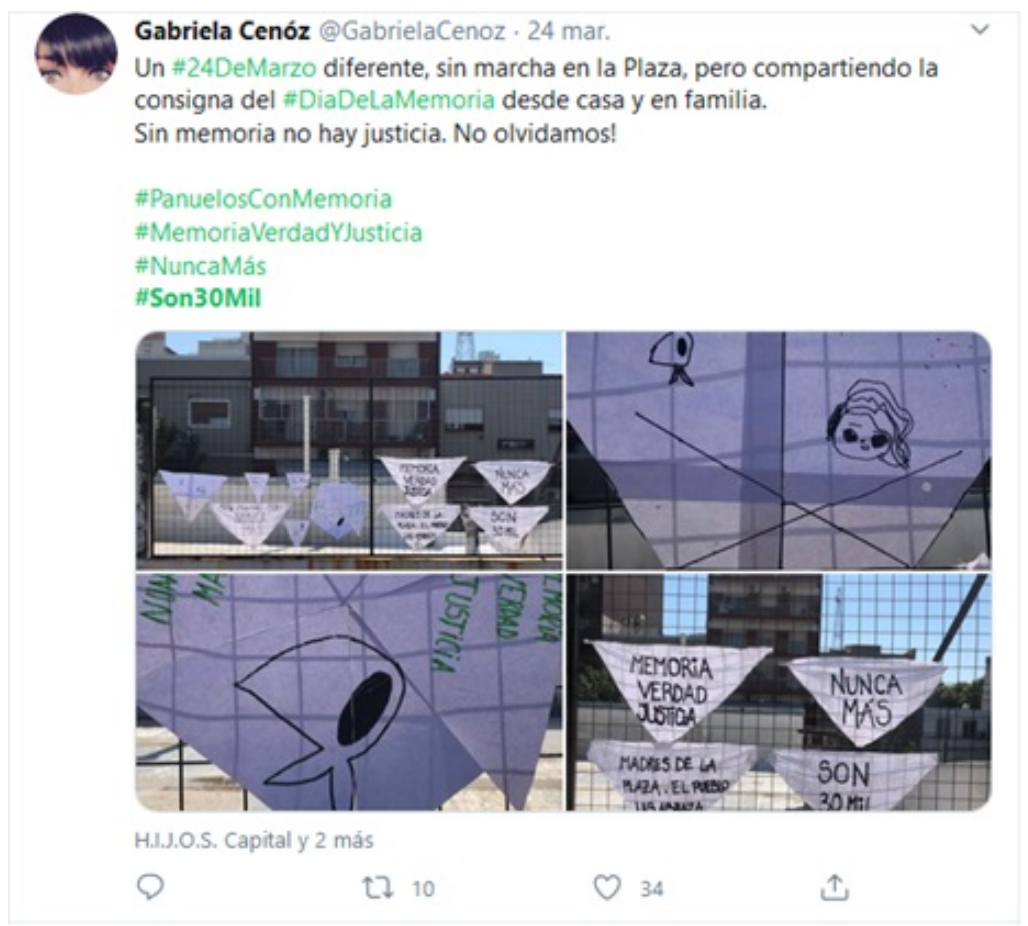

Imagen 6: Tuit personal. Los trabajos de las memorias sobre el 24 de marzo en el presente incorporan y reivindican nuevas luchas y demandas actuales. Pañuelos blancos y verdes para la Campaña \#PañuelazoConMemoria. Captura de pantalla, Twitter, 24 de marzo de 2020.

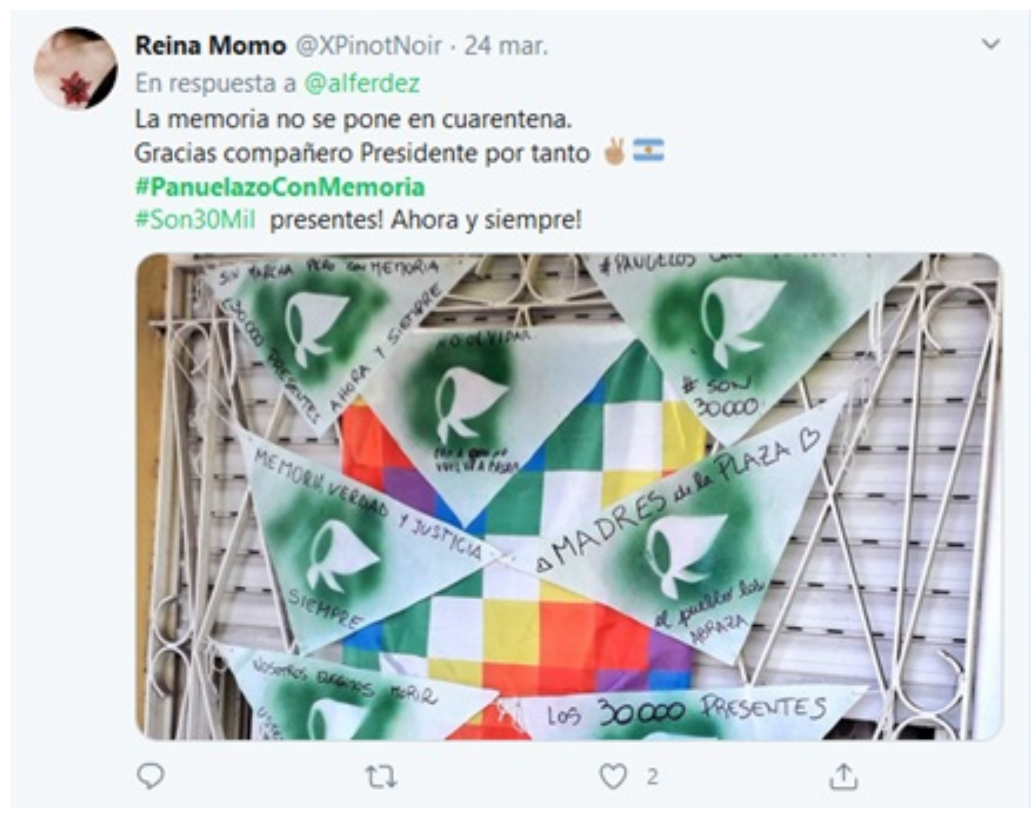


Imagen 7: Tuit de ATE (Asociación Trabajadores del Estado), trabajadores de la Administración Nacional de Laboratorios e Institutos de Salud "Dr. Carlos G. Malbrán", campaña \#PañuelazoConMemoria. Captura de pantalla, Twitter, 24 de marzo de 2020.

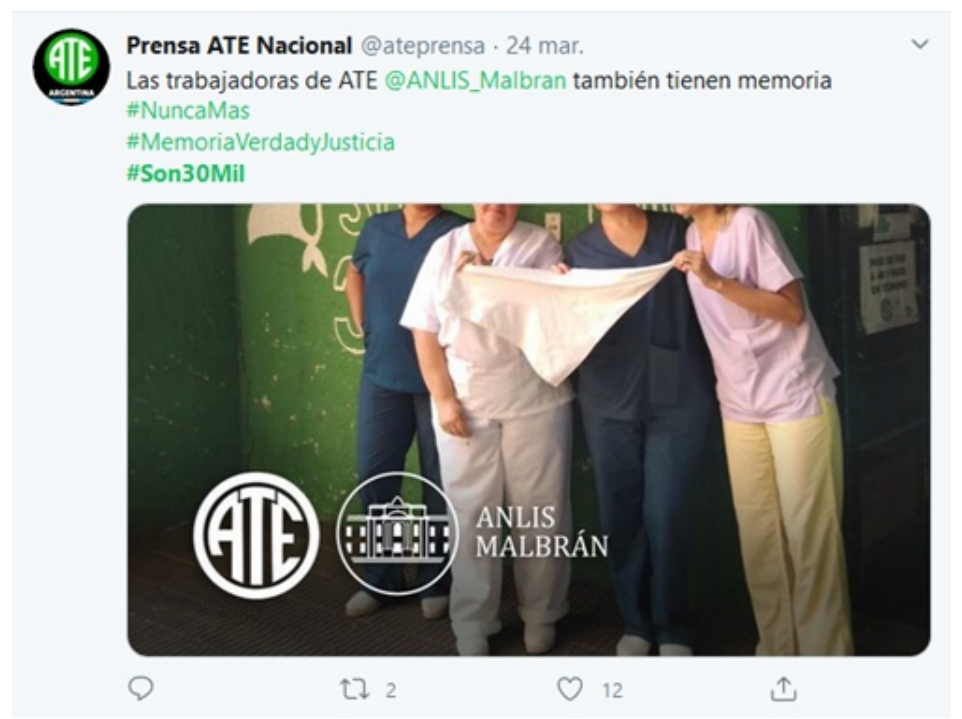

Imagen 8: Las redes sociales permiten un flujo mayor de contacto y participación con quienes no se encuentran en el país. Desde México se sumaron a la Campaña México, campaña \#PañuelazoConMemoria. Captura de pantalla, Twitter, 24 de marzo de 2020.

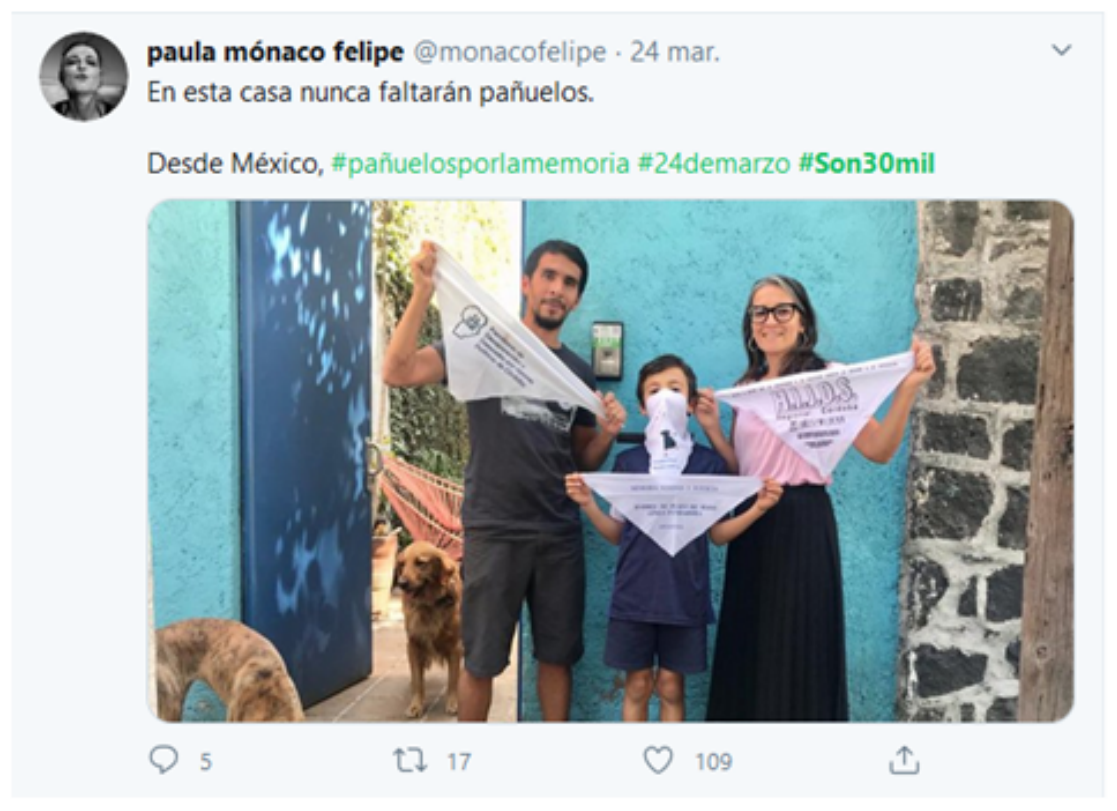


Imagen 9: Retuit de la Agencia Presentes de un tuit personal. Visibilidad de la comunidad LGBT + “30.400”, Campaña \#PañuelazoConMemoria. Captura de pantalla, Twitter, 24 de marzo de 2020.

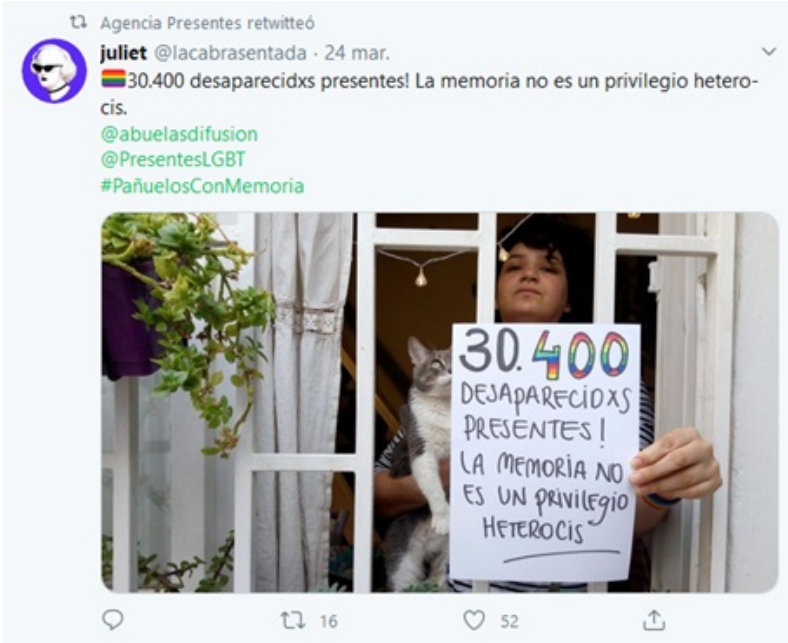

En el caso del 24M21, como ya dijimos, por las disposiciones del contexto DISPO, se configuró otro paisaje visual. Por un lado, al igual que en 2020 se continuó con el uso de los pañuelos blancos en los frentes de los hogares y su fotografía circulando por las redes sociales. En Instagram, se crearon gifts específicos en alusión al 24 de marzo donde el pañuelo blanco fue el protagonista. Recordemos que el gif (graphics interchange format) es una de las opciones visuales y textuales que aparece y puede ser adosada al momento de publicar una historia en Instagram.

Imágenes 10 y 11: Gifs alusivos al 24 de marzo, Instagram, 24 de marzo de 2021.
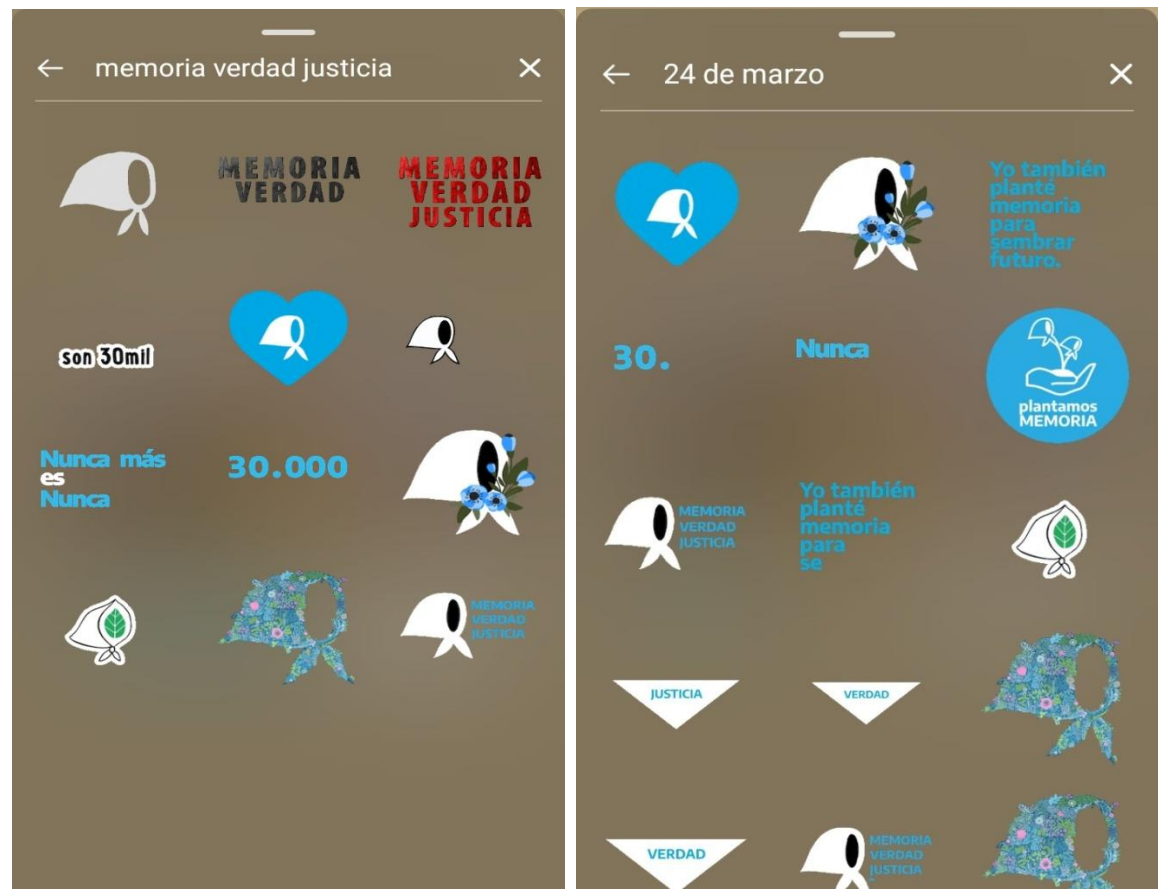

Por otro lado, y a diferencia del año anterior, volvió a visibilizarse la intervención en el espacio público. De este modo, se llevaron adelante homenajes públicos y, como ya mencionamos, la campaña Plantar Memoria realizada en diferentes instituciones (educativas, sindicales, de la salud, entre otras) con la particularidad de que las fotografías difundidas dieron cuenta de la incorporación de las marcas de la pandemia: las personas reunidas usando barbijos, algunas con distanciamiento social. 
Imágenes 12 y 13: Flyers de la Campaña "Plantemos Memoria” para las redes sociales. 24 de marzo de 2021.

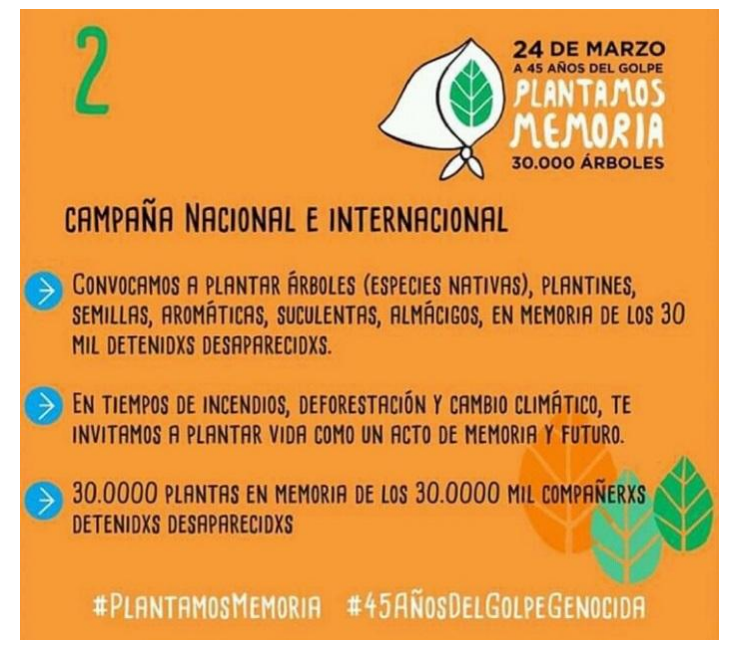

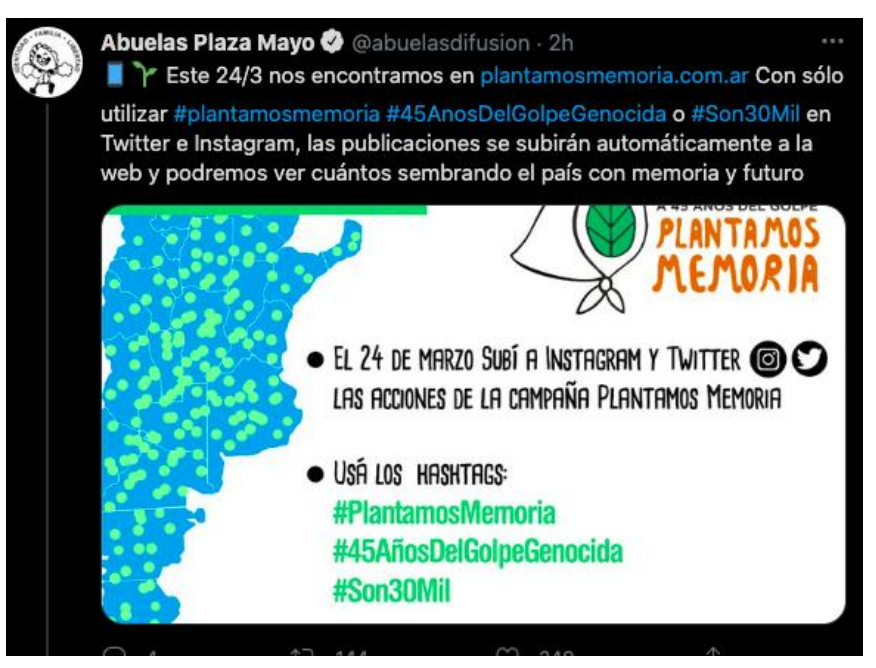

Imágenes 14, 15, 16 y 17: Abuelas de Plaza de Mayo compartieron en sus historias las respuestas a la Campaña "Plantemos Memoria" a través de registros fotográficos de las plantaciones. Abuelas Difusión, captura de pantalla, Instagram, 24 de marzo de 2021.
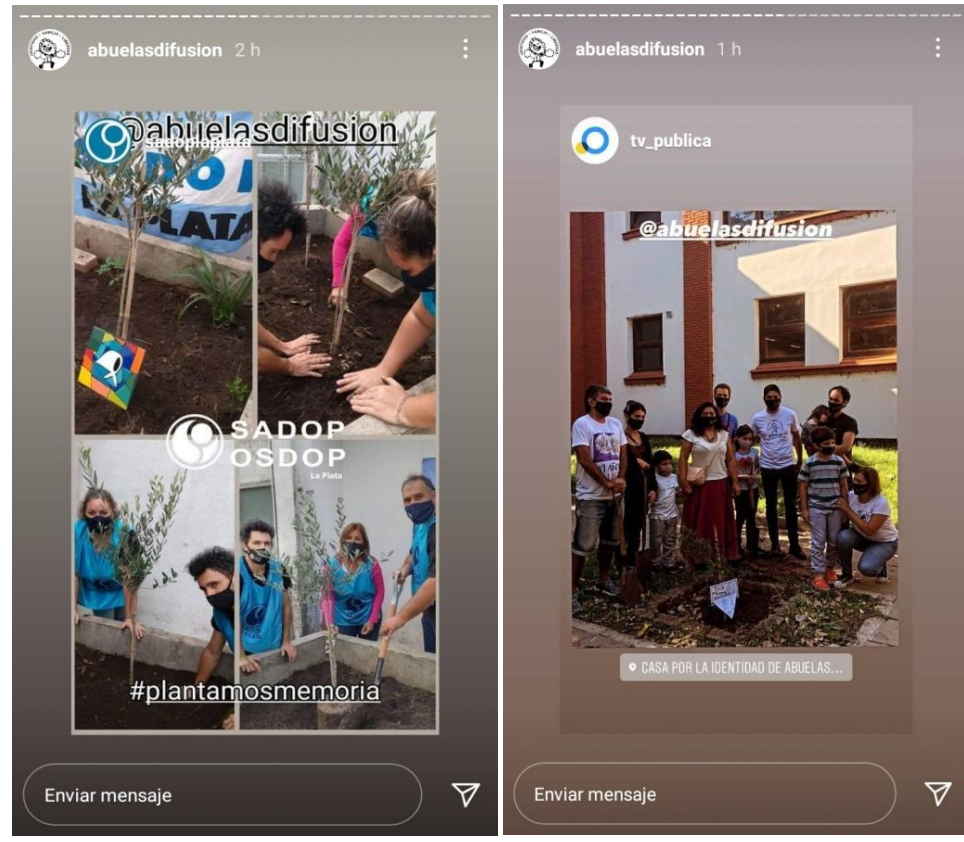

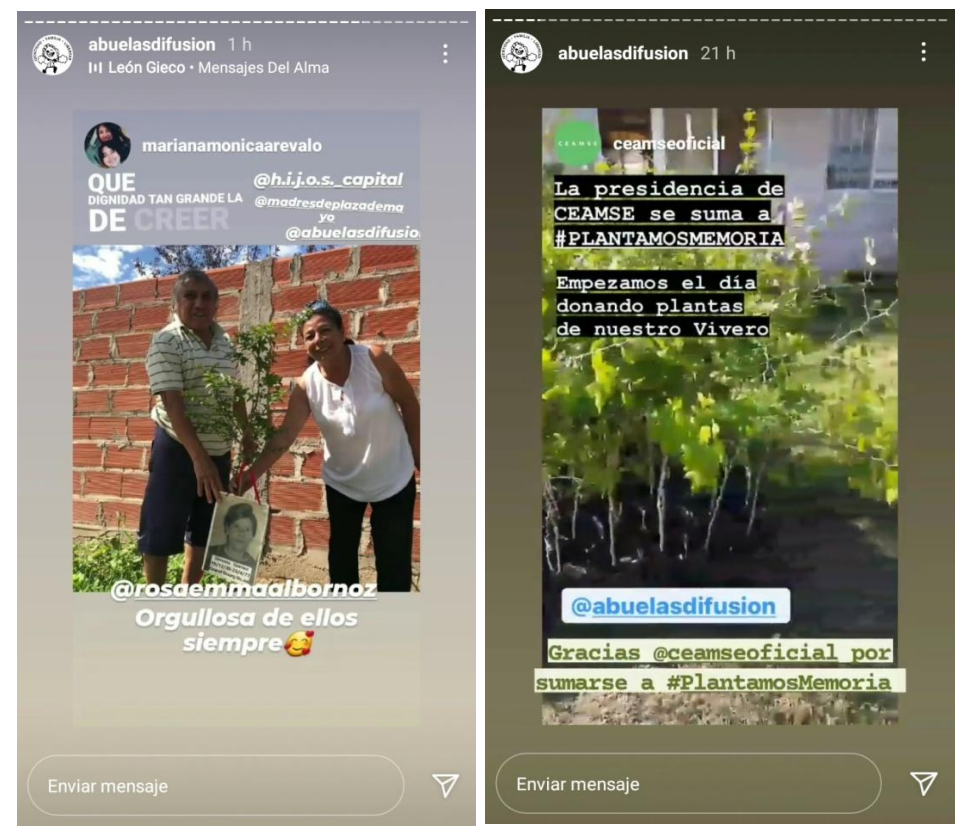

Imágenes 18 y 19: Campaña "Plantemos Memoria", Facultad de Humanidades y Ciencias de la Educación, UNLP, Ensenada, 24 de marzo de 2021. Fotografía: FaHCE.
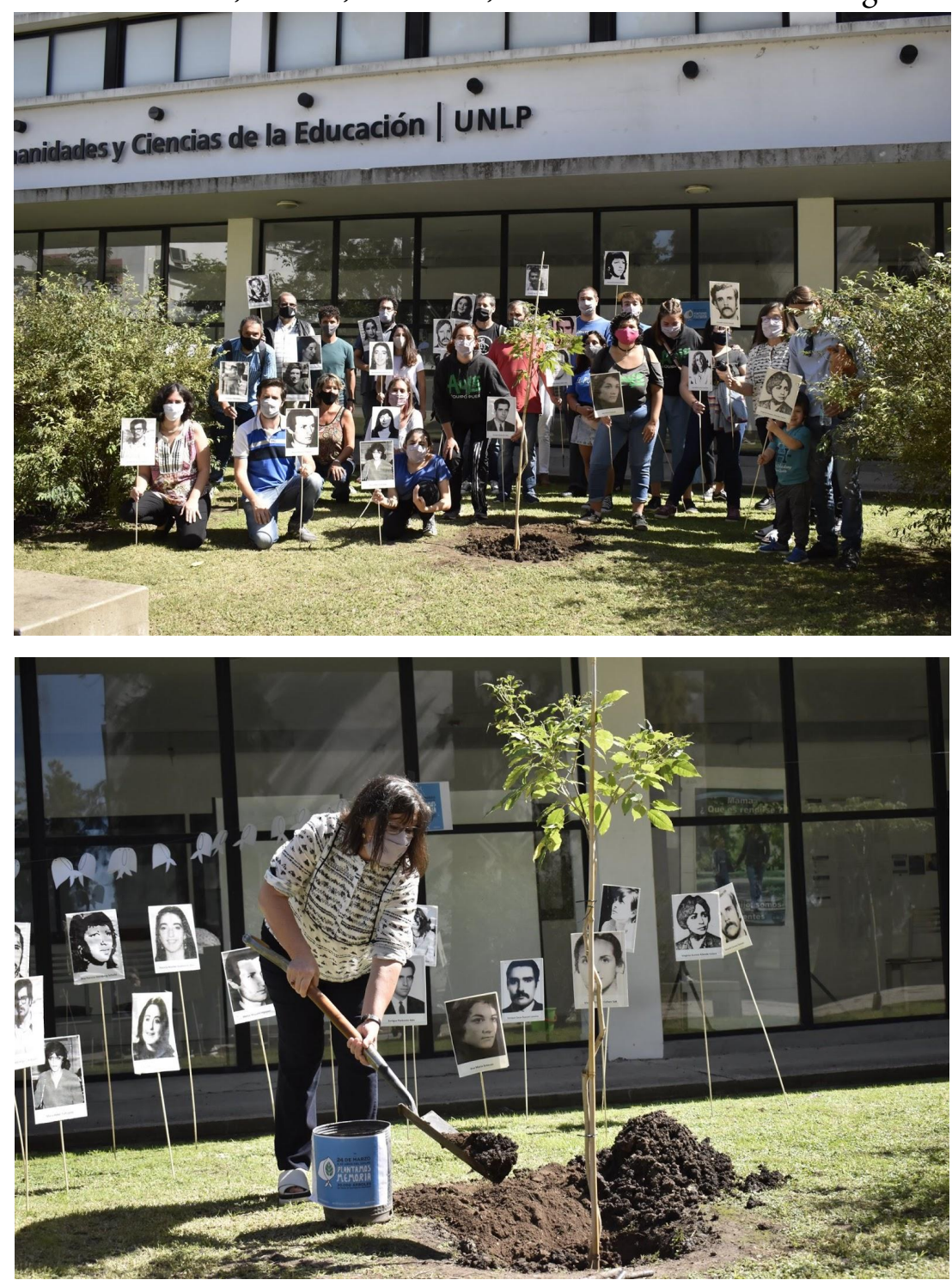
Imágenes 20 y 21: La organización Nietes también compartió en sus historias la Campaña "Plantemos Memoria" a través de registros fotográficos de las plantaciones, captura de pantalla, Instagram, 24 de marzo de 2021.
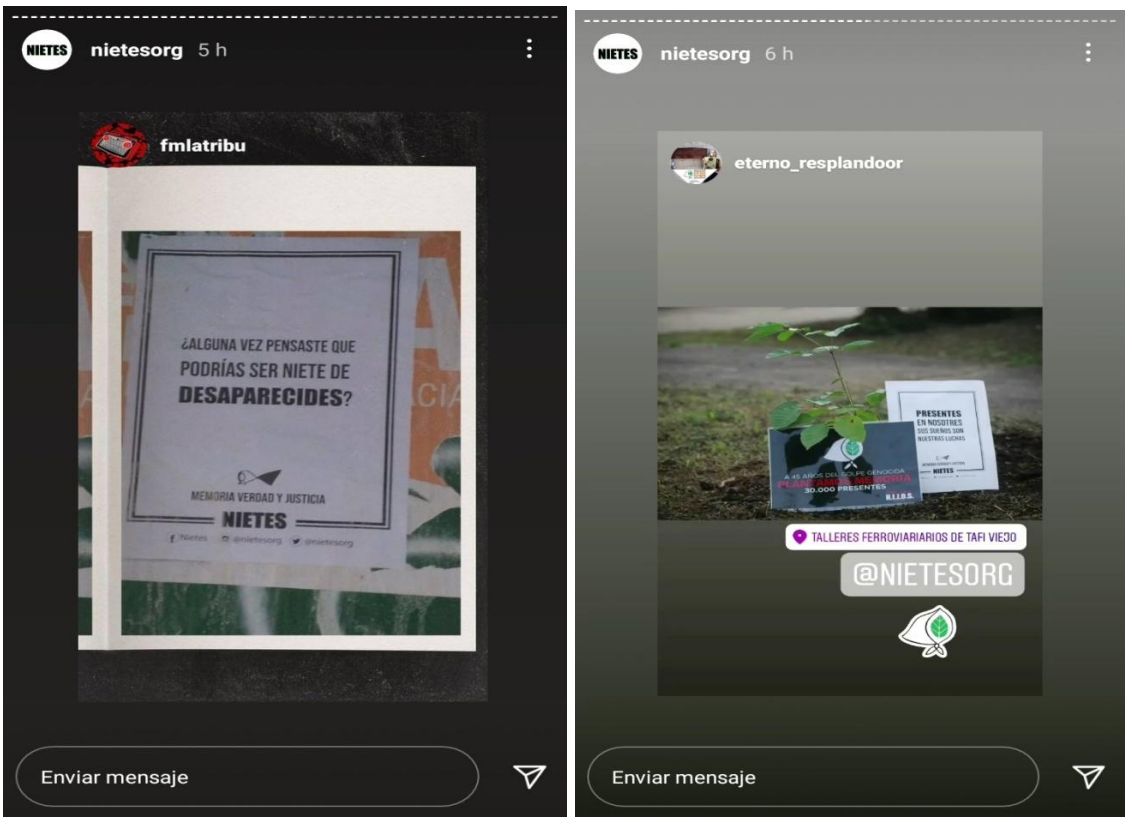

Imágenes 22 y 23: El perfil Proyectorazo compartió en sus historias proyecciones en el espacio público realizadas en diferentes ciudades del país, capturas de pantalla, Instagram, 24 de marzo de 2021.
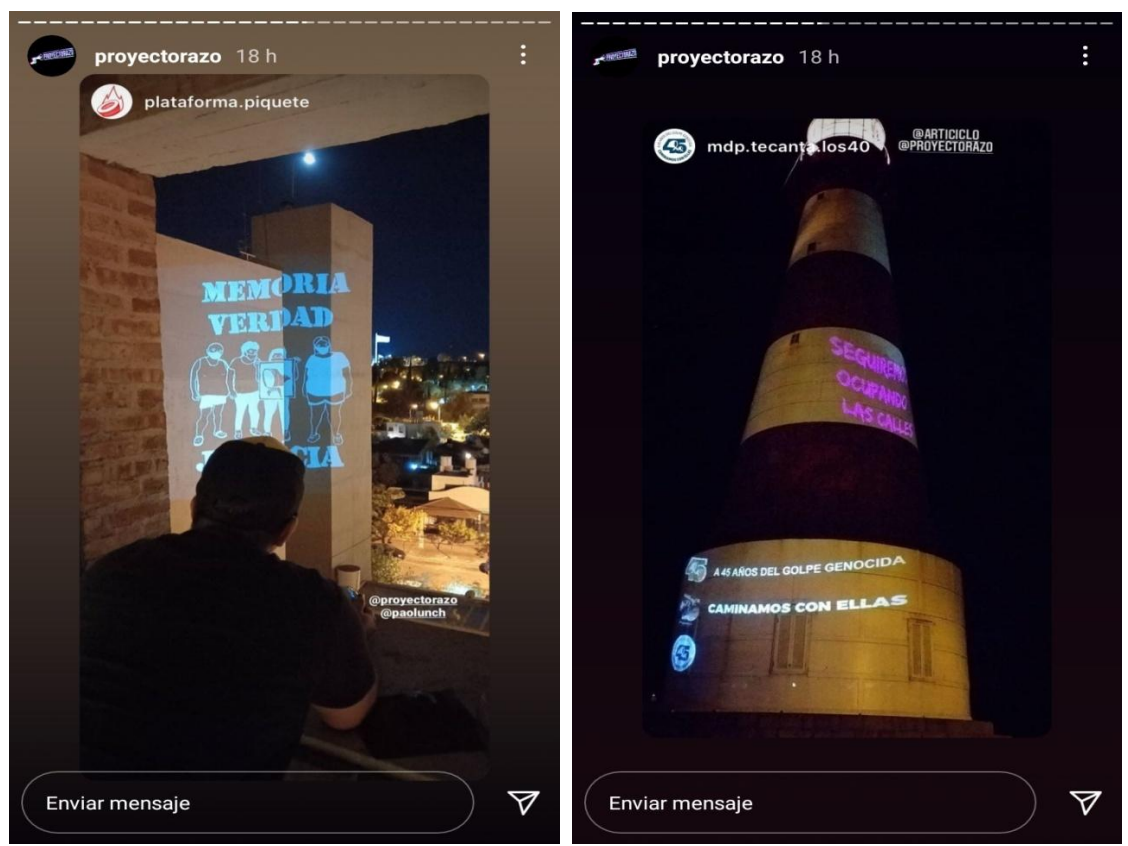

Por último, se realizaron marchas en distintas ciudades del país, que en el caso de la ciudad de La Plata, adquirió el formato de caravana de autos, siendo los vehículos los soportes de las fotografías de les desaparecides que, como ya dijimos, también se colgaron en la Plaza San Martín. En este sentido, no hubo aglomeración de personas aunque sí de autos. Al uso de las clásicas fotografías en blanco y negro, se le sumaron banderas con consignas como "Nunca más", "Memoria, verdad y justicia”, "Son 30000", entre otras. Por último, también estuvo presente la imagen de Jorge Julio López, detenido y desaparecido en 1976 y vuelto a desaparecer el 18 de septiembre de 2006, tras declarar en el juicio al ex represor Miguel Etchecolatz. 
Imagen 24: Flyer de la convocatoria “Caravana. La memoria está en la calle”, 24 de marzo de 2021.

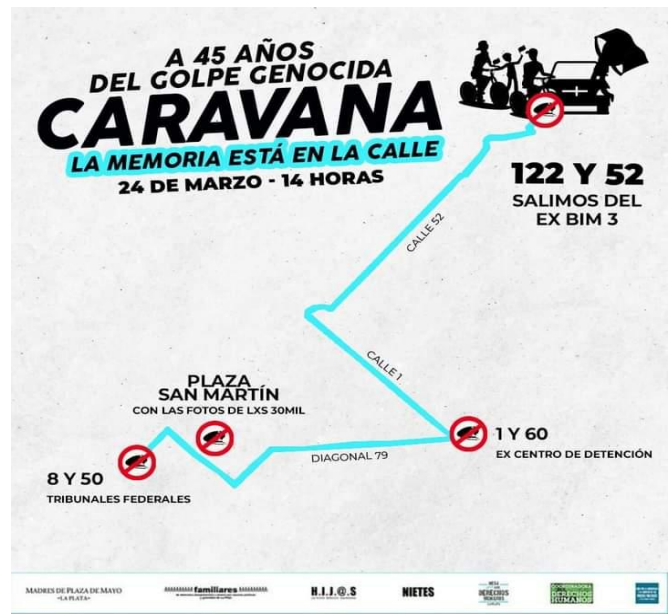

Imagen 25: "Caravana. La memoria está en la calle", La Plata. Fotografía de Melina Jean Jean, 24 de marzo 2021.

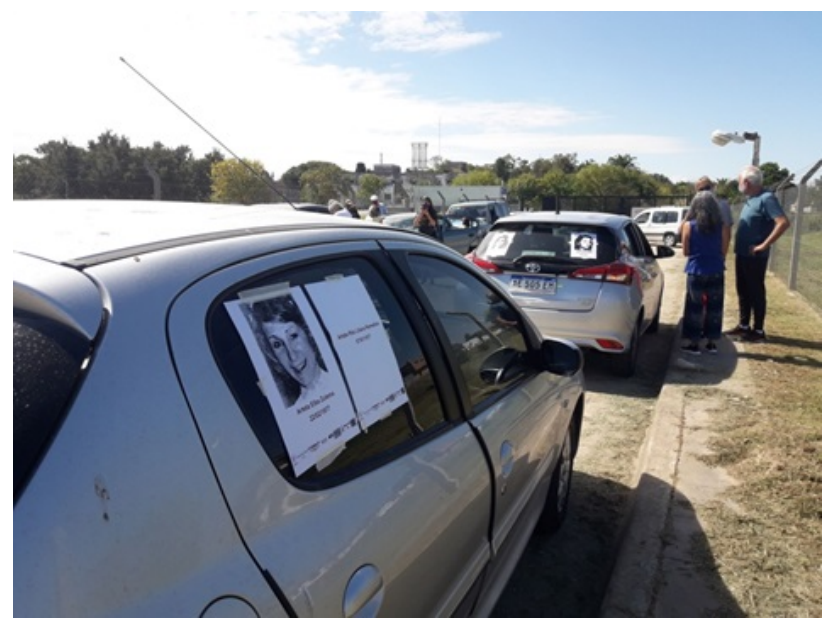

Imagen 26: "Caravana. La memoria está en la calle, La Plata”. Fotografía de Melina Jean Jean, 24 de marzo de 2021.

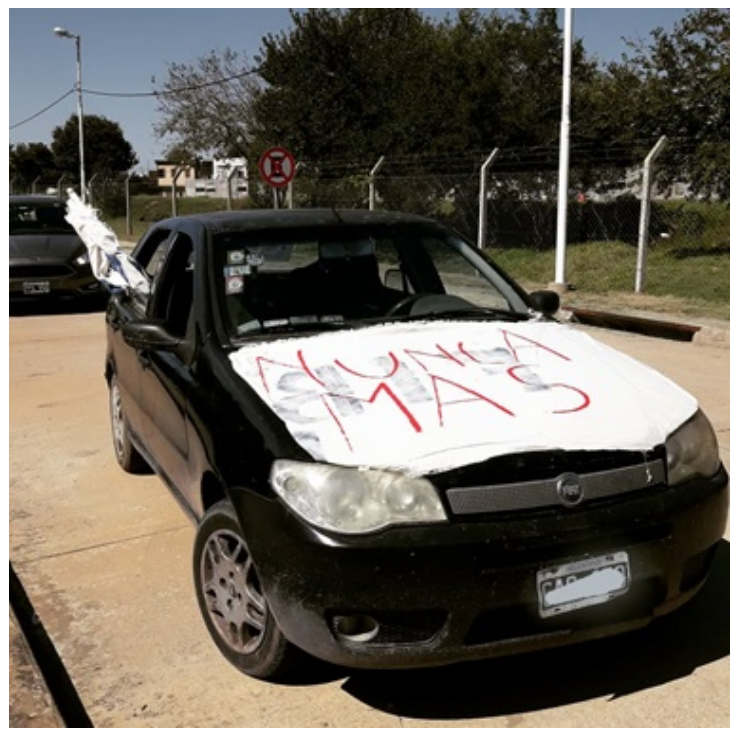


Imagen 27: Imagen de Jorge Julio López, “Caravana. La memoria está en la calle”, La Plata. Fotografía de Melina Jean Jean, 24 de marzo de 2021.

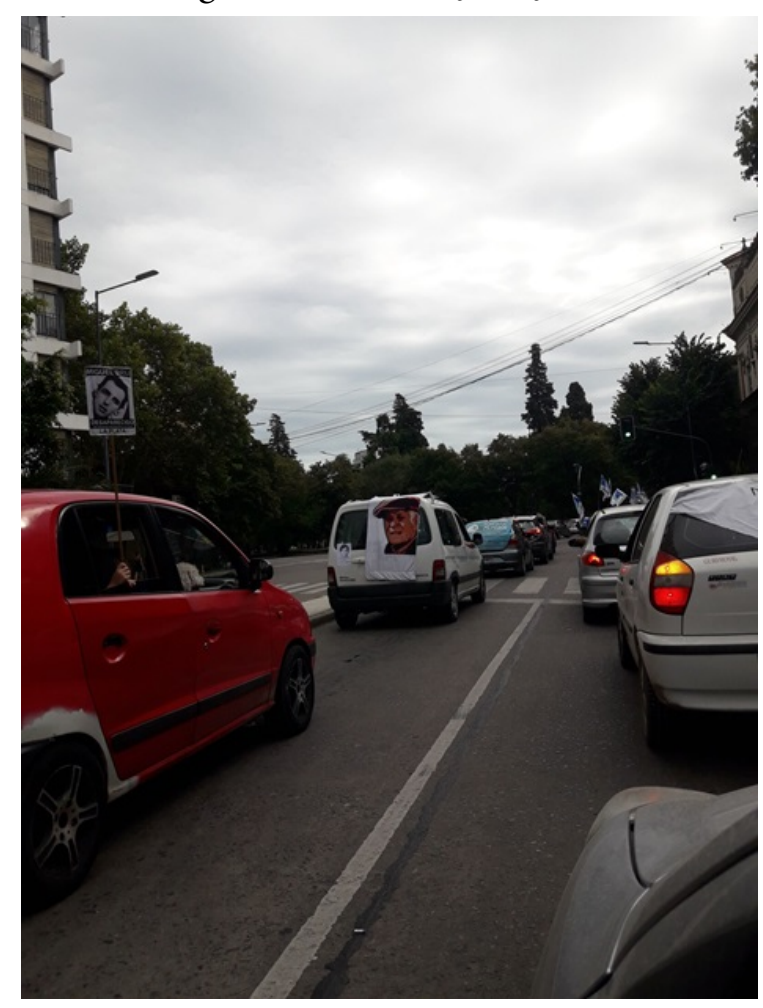

Imagen 28: “Caravana. La memoria está en la calle”, La Plata. Fotografía de Melina Jean Jean, 24 de marzo de 2021

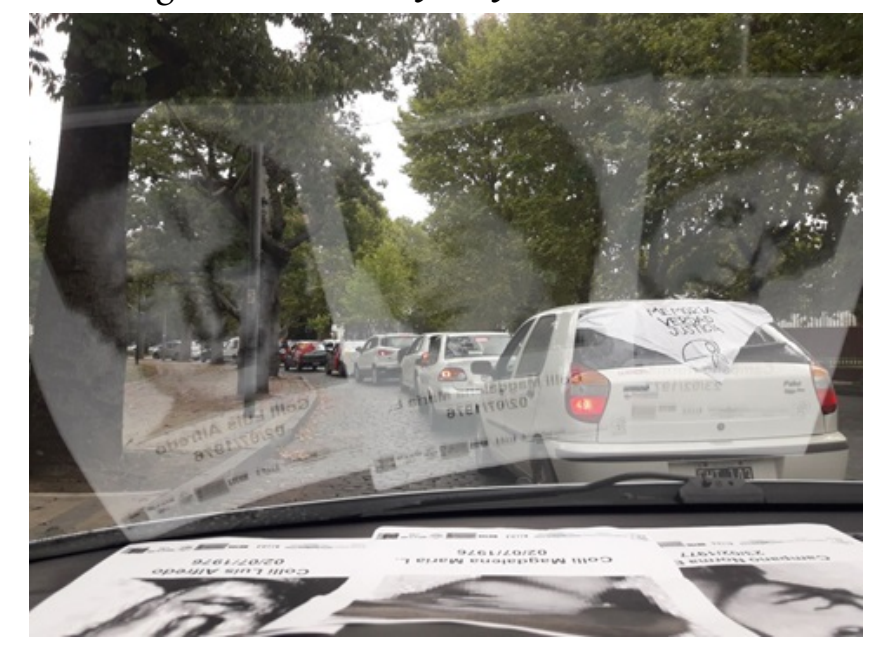

\section{A MODO DE CIERRE}

¿Qué se puede ver y qué no en una época? ¿Qué vemos y cómo lo vemos? Según Michel Foucault (1982), todo momento histórico se caracteriza por una visibilidad y decibilidad específicas, es decir, por ciertas maneras de ver y de decir que no pueden entenderse por fuera de una red de relaciones, saberes, tecnologías e instituciones. Desde los Estudios visuales, Martin Jay (2003), retoma esta idea de Foucault para hablar de 
lo que denomina regímenes escópicos, es decir el modo de ver que prevalece en un determinado momento histórico, lo que marca límites de lo que se puede ver y lo que no, lo que se esconde o niega. En este sentido, hablar de regímenes de visibilidad de una época nos permite dar cuenta de aquello que es posible ver y, por lo tanto, lo que es posible comprender de esta. Como dice Brea, el ver es un:

acto complejo y cultural y políticamente construido, y que lo que conocemos y vemos depende, justamente, de nuestra pertenencia y participación de uno u otro régimen escópico (...) (2007: 148).

Es decir, la forma de entender una época se relaciona con lo que podemos ver en ella. ¿Podemos pensar que estamos ante un nuevo régimen de visibilidad? ¿O es un régimen de visibilidad atravesado por "nuevas prótesis", dispositivos y herramientas -como la computadora, el celular y las redes sociales a ellos asociados-, que lo que nos permiten es un procesamiento y una circulación de imágenes a una velocidad mayor que antes? En el caso de lo que hemos analizado aquí -y en otro tipo de expresiones contemporáneas- la dimensión virtual aparece tanto como una extensión de las manifestaciones callejeras como un espacio de producción en sí, en ambos casos un espacio de disputa. Lo que pasa en la virtualidad importa tanto como lo que pasa en la calle, y más cuando la calle deja de ser el espacio protagónico por una razón de fuerza mayor, como lo es el contexto de pandemia. En un artículo reciente, Rodríguez, Gamarnik y Vázquez (2021) reflexionan sobre los vínculos entre memoria, imágenes y ciudad a partir de una selección de imágenes del 24 de marzo de 2020 en pandemia. En dicho texto, proponen pensar que:

la fotografía, la virtualidad, el uso de las redes sociales y las nuevas formas de expresión y protesta social surgidas durante el distanciamiento social permitieron reinventar el aniversario del golpe de Estado (...) [donde] los espacios de cada hogar que quedan en contacto visual con el exterior se volvieron superficies de expresión política (Rodríguez, Gamarnik y Vázquez, 2021: 291-292).

Entonces, ¿cómo hacerse ver y escuchar en una nueva situación que veta ciertas opciones pero que potencia otras? Observamos que, dadas las características específicas generadas por el inicio de la pandemia, el 24M20 estuvo signado por un repliegue del activismo hacia el espacio virtual y las redes sociales (y otros medios como la radio y televisión) y hacia el rincón más íntimo del hogar ${ }^{21}$, lo cual no obturó, sin embargo, la posibilidad de generar una gran comunidad online. Consideramos que las redes sociales permitieron que el activismo del movimiento de derechos humanos en Argentina, en torno a la conmemoración del 24 de marzo en pandemia, no perdiera su sentido social, político y colectivo. El ciberactivismo que se organizó para la ocasión fue aceptado y ampliamente respaldado por los sectores sociales que adhieren a la causa todos los años. Sin embargo, creemos que esto no reemplaza el peso de la manifestación en las calles y el impacto visual y emotivo que genera la multitudinaria e histórica marcha a Plaza de Mayo.

Podemos preguntarnos ¿Qué quedará de esta nueva experiencia en el futuro post pandemia? Un año después, podemos decir que se reavivó el activismo offline en las calles, aunque controlado/restringido y atravesado además por los protocolos aprendidos para el cuidado contra el Covid-19 (uso del barbijo, distancia social, etc.), sin dejar de lado la funcionalidad y la potencia de las redes sociales que demostró el activismo online del 24M20. Sin dudas, observamos aquí una (re)configuración en los modos de hacer memoria colectiva que implicó nuevos desafíos a la hora de pensar su defensa/disputa y transmisión. Las estrategias visuales renovaron tanto las materialidades y formas, como los modos de circulación del repertorio iconográfico del movimiento de derechos humanos ${ }^{22}$, a la vez que se sumaron voces, reclamos y luchas del presente que reavivaron el sentido de los trabajos de memoria para visibilizar problemáticas actuales y la ampliación de derechos que consoliden la democracia. En ese sentido, en las últimas conmemoraciones aparecen algunos temas que se van tornando relevantes: por un lado, la presencia de la agenda de género (desde hace ya tiempo) para interpelar ese pasado, activando nuevas memorias y también denunciando las injusticias del presente (algo que, como señalamos, aparece simbolizado en los pañuelos verdes que enlazan con el pañuelo blanco). Al calor del auge del movimiento de mujeres, LGTB + y los feminismos de los últimos 
años, las consignas, las declaraciones, intervenciones y homenajes del $24 \mathrm{M}$ tienen en su gran mayoría esa huella que llegó para quedarse (como vimos en las imágenes, la consigna "son 30.400" se va tornando cada vez más presente, lo mismo ocurre con el uso de la " $e$ " o la " $\mathrm{x}$ " que propone el lenguaje inclusivo, para mencionar a "les desaparecides" o "lxs desaparecidxs"). Por otro lado, la convocatoria de plantar 30.000 árboles lanzada por los organismos de derechos humanos, bajo el lema "los pueblos que siembran memoria tienen porvenir" dialoga con el contexto de una pandemia que amenaza la vida humana e instala la incertidumbre poniendo en crisis ese futuro. El comunicado de la iniciativa señala que "La Memoria, al igual que la semilla, viene cargada de futuro. Contiene toda la información genética para poder llegar a ser el árbol que late en su destino. En tiempos de incendios, deforestación y cambio climático, invitamos a plantar vida como un acto de memoria y futuro" ${ }^{23}$. Así, el acto de sembrar se vuelve profundamente político e interpela nuevas maneras de habitar un presente atravesado también por las agendas del ecologismo, el cuidado del planeta y las luchas contra el extractivismo ${ }^{24}$. Tendremos que esperar para observar el devenir (¿y las potencias?) de estas visualidades emergentes en pandemia en el futuro próximo.

\section{RefERENCiAS}

Amaya Trujillo, J., \& García Hernández, A. (2018). De la memoria colectiva a las nuevas ecologías de la memoria: derroteros en la investigación sobre memoria, medios y tecnologías de la comunicación. ComHumanitas: Revista Cientifica De Comunicación, 8(2), 1-21. Disponible en: https://www.comhumanitas.org/index.php/comhuma nitas/article/view/140

Burucúa, J. E. y Kwiatkowski N. (2014). Cómo sucedieron estas cosas. Representar masacres y genocidios. Madrid, Buenos Aires: Katz Editores.

Brea, J. Luis (2007). Cambio de régimen escópico: del inconsciente óptico a la e-image. Estudios visuales. Ensayo, teoria y crítica de la cultura visual y el arte contemporáneo, 4, 145-163.

Bresciano, J. A. y Gil, T. (comp.) (2015). Historiografía, giro digital y globalización. Reflexiones teóricas y prácticas investigativas. Montevideo: Ediciones Cruz del Sur. Disponible en: http://lhs.unb.br/lhs/wp-content/obras/g il_bresciano.pdf

Da Silva Catela, L. (2005). Formas de las memorias. Etnografía de las marcas, usos y reinterpretaciones de las memorias políticas en Argentina. En: Territorios en conflicto ¿Por qué y para qué hacer patrimonio?. VII Seminario sobre Patrimonio Cultural. Biblioteca de Santiago de Chile: Editorial DIVAN, 12 - 29.

Da Silva Catela, L. [2001] (2009). No habrá flores en la tumba del pasado. La experiencia de reconstrucción del mundo de los familiares de desaparecidos. La Plata: Al Margen.

Ejido, A. y Eiroa, M. (2017). Redes sociales, historia y memoria digital de la represión de mujeres en el franquismo. Revista de Historiografía, 27, pp. 341-361, https://doi.org/10.20318/revhisto.2017.3977

Erll, A., y Nünning, A. (2011). Cultural Memory Studies: An International and Interdisciplinary Handbook. Berlín y Nueva York. Walter de Gruyter y A. Rigney (Eds.), Mediation, Remediation and the Dinamics of Cultural Memory Memory in Culture (pp. 185-352). Hampshire y Nueva York: Palgrave Macmillan.

Feld, C. (2010). Imagen, memoria y desaparición. Una reflexión sobre los diversos soportes audiovisuales de la memoria. Aletheia, 1(1), octubre. Disponible en: http://www.aletheia.fahce.unlp.edu.ar/numeros/numero-1/p dfs/Feld-\%20Aletheia\%20Vol\%201.N1.pdf

Foucault, M. (1982). Las palabras y las cosas: una arqueologia de las ciencias humanas. Buenos Aires: Siglo XXI.

Gamarnik, C. [PIEMMER]. (06/012020). Presentación Cora Gamarnik. Jornada Académica CHILE IMÁGENES DE LA INSURGENCIA [Archivo de video] Youtube. Recuperado de: https://www.youtube.com/watch?v=m BreCp3_dyk\&t=2s\&ab_channel=PIEMMER

Gorini, U. (2006). La rebelión de las Madres. Historia de las madres de Plaza de Mayo. Buenos Aires: Grupo Editorial Norma.

Huyssen, A. (2002). En busca del futuro perdido. Cultura y memoria en tiempos de globalización. México: FCE. 
Jay, M. (2003). Campos de fuerza. Entre la historia intelectual y la critica cultural. Buenos Aires: Paidós.

Jelin, E. (2002). Los trabajos de la memoria. Madrid: Siglo XXI.

Legarralde, M., y Brugaletta, F. (2017). Introducción al Dossier Pedagogía de la Memoria. Aletheia, 7(14), 1-7. Disponible en: https://www.aletheia.fahce.unlp.edu.ar/article/view

Longoni, A., Bruzzone, G. A. (2008). El Siluetazo. Buenos Aires: Adriana Hidalgo.

Longoni, A. (2010). Arte y Política. Políticas visuales del movimiento de derechos humanos desde la última dictadura: fotos, siluetas y escraches. Aletheia 1(1). Disponible en: http://www.aletheia.fahce.unlp.edu.ar/numeros/numero-1/ana-longoni.-arte-ypolitica.-politicas-visualesdel-movimiento-de-derechos-humanos-desde-laultima-dictadura-fotos-siluetas-y-escraches

Mandolessi, S. (2019). Discusión: Memorias digitales y desaparición. El caso Ayotzinapa. Revista Transas, Letras y Artes de América Latina. Archivo. 26 de septiembre de 2019. Disponible en: https://www.revistatransas.com/2 019/09/26/memorias-digitales-y-desaparicion-ayotzinapa/

Mitchell, W. T. (2009). Teoria de la imagen. Madrid: Ediciones Akal.

Rodríguez, M. G., Gamarnik, C., y Vázquez, C. (2021). La memoria en tiempos de pandemia. Registro visual del 24 de marzo de 2020 en Argentina. Revista TOMO, 38, 287-306.

Runnel, P.; Pruulmann-Vengerfeldt, P; Viires, P.; Laak, M. (Eds.). (2013). The Digital Turn. User's Practices and Cultural Transformations. Frankfurt; Nueva York: Peter Lang.

Schindel, E. (2009). Insertar el pasado en el presente: memoria y espacio urbano. Política y Cultura (México UAM), 31. Westera, W. (2013). The digital turn. How the Internet Transforms Our Existence. United Kingdom: AuthorHouse.

\section{Notas}

1 Para detalles sobre la organización del primer 24 de marzo en Pandemia, 2020, puede verse el trabajo de V. Vegh Weis, "La memoria en tiempo de pandemia" disponible en : https://www.clacso.org/la-memoria-en-tiempo-de-pandemia/

2 Las Madres de Plaza de Mayo utilizaron por primera vez el pañuelo blanco en octubre del año 1977, para participar de la peregrinación que cada año se realiza al Santuario de Luján. Si bien en los inicios algunas mujeres habían utilizado un clavo de carpintero para identificarse entre sí (Gorini, 2006), fue a partir de dicho evento que decidieron utilizar el pañal, para poder distinguirse rápidamente en la multitud. El pañal blanco, símbolo de nacimiento, vida y pureza, se transformaría rápidamente en pañuelo y en el distintivo del grupo de mujeres, que lo utilizarían exclusivamente en los espacios públicos para identificarse, una vez congregadas un grupo importante de ellas (Da Silva Catela, 2005). Con el tiempo serían intervenidos con el bordado de los nombres de sus hijos/as y la consigna “Aparición con vida”. El pañuelo blanco se ha constituido en un emblema nacional e internacional de enorme poder simbólico, tornándose una referencia del movimiento de derechos humanos, pero también de nuevas luchas y demandas ciudadanas.

3 Abuelas Plaza de Mayo (20/03/20) Pañuelazo blanco (Twitter) Recuperado de: https://twitter.com/abuelasdifusion/ status/1241087839590387713?lang=es

4 El 3 de mayo de 2017 la Corte Suprema dictó un fallo que habilitaba que los perpetradores condenados por delitos de lesa humanidad pudieran computar doble el tiempo que estuvieron detenidos antes de contar con una sentencia firme, a partir de los dos años de prisión preventiva. El fallo se apoyaba en la ley 24.390, sancionada en 1994 y derogada en 2001, que habilitaba la reducción de las condenas para quienes se encontraran en prisión preventiva sin condena firme, pero se aplicaba por primera vez a un delito de lesa humanidad (en concreto a Luis Munia, condenado en 2013 por su participación en el comando paramilitar interno del Hospital Posadas), sentando de este modo un precedente peligroso que permitiría liberar o reducir las penas de otros represores apresados. La medida generó un gran repudio por parte del movimiento de derechos humanos, organizaciones sociales y políticas, y gran parte de la ciudadanía que se manifestó masivamente el 10 de mayo en la Plaza de Mayo. Ese día todes les presentes, cuando las Madres lo indicaron durante el acto, levantaron los pañuelos en alto, formando una marea blanca impactante, nunca antes vista. Un pañuelazo público y masivo en la histórica plaza, que demostró el apoyo y la reivindicación social a la lucha del movimiento de derechos humanos y sobre todo, la defensa de las conquistas logradas. Para ver la icónica fotografía del pañuelazo, véase: "Mar de pañuelos", la impactante foto de la marcha contra el 2x1 que emocionó a todos" (11/05/17) Los Andes, periodismo de verdad. Recuperado de: https://www.losandes.com.ar/-mar-de-panuelos-la-impactante-foto-de-la-marcha-contra-el -2x1-que-emociono-a-todos/ 
5 Véase más información en: Abuelas de Plaza de Mayo y otros organismos de DDHH no marcharán el 24 de marzo (18/02/21) Télam. Recuperado de: https://www.telam.com.ar/notas/202102/544937-24-de-marzo-marcha-organis mos-ddhh-abuelas.html

6 Véase más información en: \#PlantamosMemoria por la verdad y la justicia (2021) Sitio web https://plantamosmemo ria.com.ar/

7 Véase más información en: A 45 años del Golpe Plantamos Memoria con Raíces bonaerenses (02/03/21) Sección de noticias del Gobierno de la Provincia de Buenos Aires. Recuperado de: https://www.gba.gob.ar/derechoshumanos/notici as/45_a\%C3\%B1os_del_golpe_\%E2\%80\%9Cplantamos_memoria_con_ra\%C3\%ADces_bonaerenses\%E2\%80\%9D

8 Véase en: El Gobierno emitió una proyección sobre el frente de Casa Rosada en homenaje a las Madres y Abuelas (24/03/21) Télam [Archivo de video] recuperado de: https://www.youtube.com/watch?v=EiQ1vSQVecY\&t=12s\& ab_channel=T\%C3\%A9lam

9 Véase: Con la tradicional vigilia se conmemoró un nuevo aniversario del Golpe de Estado de 1976 (24/03/21) Sección de Noticias Municipalidad de Berisso, recuperado de: http://www.berisso.gov.ar/noticia/con-la-tradicional-vigilia-se-co nmemoro-un-nuevo-aniversario-del-golpe-de-estado-de-1976

10 Pueden verse algunas fotografías en: Comisión Permanente Por La Memoria - Berisso (25/03/21) Facebook. Recuperado de: https://www.facebook.com/Comisi\%C3\%B3n-Permanente-Por-La-Memoria-Berisso-19617055107 26635/potos/pcb.2996373650593144/2996372617259914/

11 La transmisión de la vigilia puede verse completa en: FM Difusión Berisso (23/03/21) Vigilia por el Día Nacional de la Memoria, Facebook [Archivo de video]. Recuperado de: https://www.facebook.com/watch/live/?v=13307650872 92602\&ref=watch_permalink

12 Véase: Acto en el Astillero en el Día Nacional de la Memoria por la Verdad y la Justicia (25/02/21) Berisso Ciudad, portal de Noticias. Recuperado de: https://www.berissociudad.com.ar/nota.asp?n=\&id=20197

13 Véase: Subsecretaría de Derechos Humanos Ensenada (25/03/21) Facebook, recuperado de: https://www.facebook.com/Subsecretar\%C3\%ADa-de-Derechos-Humanos-Ensenada-575603145929321/photo s/pcb.1843418595814430/1843416122481344/

14 Véase: Subsecretaría de Derechos Humanos Ensenada (29/03/21) Facebook, recuperado de: https://www.facebook.com/Subsecretar\%C3\%ADa-de-Derechos-Humanos-Ensenada-575603145929321/photo s/pcb.1846512938838329/1846512612171695/

15 Véase: Subsecretaría de Derechos Humanos Ensenada (29/03/21) Facebook, recuperado de: https://www.facebook.com/Subsecretar\%C3\%ADa-de-Derechos-Humanos-Ensenada-575603145929321/photo s/pcb.1846471128842510/1846470162175940/

16 Véase: Subsecretaría de Derechos Humanos Ensenada (31/03/21) Facebook, recuperado de: https://www.facebook.com/Subsecretar\%C3\%ADa-de-Derechos-Humanos-Ensenada-575603145929321/photo s/pcb.1847990262023930/1847990038690619/

17 El 4 de octubre de 1977 un grupo de alrededor de 60 mujeres integrantes de la reciente organización Madres de Plaza de Mayo se dieron cita en el Parque Pereyra Iraola, simulando festejar la jubilación de María Adela Antokoletz. El encuentro tenía como objetivo realizar la primera asamblea en la que elegir delegadas, para la conformación de una nueva estructura organizativa, ante el aumento importante del número de integrantes del grupo (Gorini, 2006).

18 Véase: Vecinos de Villa Elisa por Memoria Verdad Justicia (24/03/21) En Villa Elisa, a 45 años del golpe civico militar genocida [Archivo de video] Facebook, recuperado de: https://fb.watch/5tuLVzx842/

19 Para más imágenes de las movilizaciones en la región (La Plata, Berisso y Ensenada) véase: Marcha y "siluetazo" en la ciudad por el Día de la Memoria (23/03/21) El Editor Platense, recuperado de: https://www.eleditorplatense.com.ar/ marcha-y-siluetazo-en-la-ciudad-por-el-dia-de-la-memoria/

$20 \mathrm{Al}$ respecto, véase: Memoria LGBT: ¿Por qué se habla de 30.400 desaparecidxs en Argentina? (23/03/20) Agencia presentes, recuperado de: https://agenciapresentes.org/2020/03/23/memoria-lgbt-por-que-se-habla-de-30-400-desapa recidxs/

21 Si bien no es un tema que se aborde en este artículo, es interesante analizar en futuras investigaciones cómo lo público y lo privado (doméstico) se reconfiguran de alguna manera en estas nuevas formas de conmemoraciones.

22 El repertorio iconográfico del movimiento de derechos humanos ha sido estudiado por Longoni y Bruzzone (2008), Da Silva Catela (2009, 2017), Estela Schindel (2009), Longoni (2010), Feld (2010) Burucúa y Kwiatkowski (2014), entre otres.

23 Véase: A 45 años del golpe genocida, plantamos memoria (10/03/21) Organismos de derechos humanos, Abuelas de Plaza de mayo. Recuperado de: https://www.abuelas.org.ar/noticia/a-anos-del-golpe-genocida-plantamos-memoria-14 25

24 Cabe señalar que dos días antes del $24 \mathrm{M}$, se realizaron movilizaciones en todo el país en el marco de la Marcha Internacional por la Crisis Climática. En Buenos Aires, movimientos sociales, organizaciones socioambientales, entre ellas Jóvenes por el Clima, se manifestaron frente al Congreso. 